\title{
The fine structure of the dynamics of seismicity before $M \geq 4.5$ earthquakes in the area of Reggio Emilia (Northern Italy)
}

\author{
Rita Di Giovambattista $\left({ }^{1}\right)$ and Yuri Tyupkin $\left({ }^{2}\right)$ \\ ( $\left.{ }^{1}\right)$ Istituto Nazionale di Geofisica, Roma, Italy \\ ${ }^{2}$ ) Geophysical Center, Russian Academy of Sciences, Moscow, Russia
}

\begin{abstract}
We present the results of studies of seismicity in the Reggio Emilia area (Northern Italy). The Istituto Nazionale di Geofisica instrumental earthquake catalogue (1975-1996) reported about three moderate-size earthquakes with $M \geq 4.5$ that occurred in this area (November 1983, May 1987, October 1996). The RTL prognostic parameter proposed by Sobolev and Tyupkin (1996a) was used for analysis. This parameter is designed in such a way that a seismic quiescence produces negative anomaly of the $R T L$ parameter in comparison to its perennial background level and an activation of seismicity initiates the growth of its value. The $R T L$ prognostic parameter indicates that all three earthquakes are preceded by activation of the seismicity. The interval between the commencement of the activation identified by $R T L$ parameter and the event itself was about one year for the 1987 and 1996 earthquakes, and about three months for the 1983 earthquake.
\end{abstract}

Key words seismicity - earthquakes - prognostic parameter-seismic quiescence-foreshock activation

\section{Introduction}

The analysis of peculiarities of seismicity before potentially disastrous earthquakes is an important part of the study of earthquake prediction. There are several methods for earthquake prediction based on the study of seismicity variations. Among them the $\mathrm{CN}$ method has been extensively applied to Italian seismicity (Costa et al., 1996). One of these approaches, based on the idea that seismic quiescence and

Mailing address: Dr. Rita Di Giovambattista, Istituto Nazionale di Geofisica, Via di Vigna Murata 605, 00143 Roma, Italy; e-mail: digiovam@marte.ingrm.it foreshock activation of seismicity consecutively follow one another in the focus of a future earthquake, was discussed by many authors (Wyss and Habermann, 1988; Purcaru and Pawelzik, 1991a,b; Sobolev, 1992, 1993; Zschau, 1995). Laboratory experiments and the results of a number of seismological studies confirm this assumption (Sobolev, 1992, 1993). The RTL prognostic parameter was proposed by Sobolev and Tyupkin (1996a) as a tool of analysis of this peculiarity of seisimicity before strong earthquakes. The algorithm of calculation of the $R T L$ prognostic parameter is based on the supposition that in the immediate vicinity of the epicenter of the future earthquake the mentioned effects are stronger the nearer the time of its occurrence. The tentative retrospective calculations of this parameter by the example of several strong earthquakes on Kamchatka, in Caucasus and in Greece produce satisfactory results 
Table I. Earthquakes with $M \geq 4.5$ occurring after 1975 in the Reggio Emilia area (Northern Italy).

\begin{tabular}{ccccccccc}
\hline Year & Month & Day & Hour & Min & Lat. & Long. & Depth & Magnitude \\
\hline 1983 & 11 & 09 & 16 & 29 & 44.70 & 10.34 & 35 & 4.9 \\
1987 & 05 & 02 & 20 & 43 & 44.81 & 10.72 & 02 & 4.5 \\
1996 & 10 & 15 & 09 & 56 & 44.78 & 10.61 & 31 & 4.8 \\
\hline
\end{tabular}

(Sobolev and Tyupkin, 1996a,b, 1998; Sobolev et al., 1997; Kapylova et al., 1998). These studies show that in the interval of 2-3 years before a strong earthquake, the seismicity of its epicentral area had a quiescence stage followed by «foreshock» activation and an earthquake occurs shortly after the $R T L$ parameter is restored to its normal level. The analysis of spatial distribution of the RTL anomaly before a strong earthquake gives that linear sizes of the anomalous area are several times larger that the source length found from empirical relation between source length and magnitude. The main shocks usually occurred at the edge of the anomalous area.

The earthquakes with $M=4.5$ and above can be dangerous for Italy and these earthquakes are the important object for prediction. However, a manifestation of effects of seismic quiescence and foreshock activation before moderate-size earthquakes is markedly weaker than before the large earthquakes mentioned above and may depend on local geotectonic conditions. Foreshock statistics of earthquakes recorded by the Italian national seismological network between 1975 and 1991 were analyzed by Console et al. (1993). These authors observed a significant tendency of foreshock activation for the Central Italy. Similar analysis of seismicity of the zone of the Po valley (Northern Italy) has shown that foreshock activation is not typical for this area. (The Po valley zone is a large area which includes the Reggio Emilia zone).

We applied the $R T L$ prognostic parameter to the analysis of peculiarity of seismicity before moderate-size earthquakes that occurred in the Reggio Emilia area

The Istituto Nazionale di Geofisica (ING) earthquake catalogue (1500 B.C. - present) reports 21 events occurring in the Reggio Emilia area and having macroseismic intensity greater than or equal to the VII degree. Some earthquakes of intensity greater than VIII occurred before 1600 and other events of higher intensity occurred in 1831 (west of the Reggio Emilia epicenter). We performed our analysis of seismicity using the instrumental part of the ING catalogue (from 1975 to 1996). It contains more than 5700 events with $M>1.4$ that occurred in the Reggio Emilia area and reports three events with $M \geq 4.5$ : the 1983 Parma earthquake, the 1987 and 1996 Reggio Emilia earthquakes (see table I).

The RTL analysis of seismicity before Reggio Emilia earthquakes with $M \geq 4.5$ show that they are forestalled by foreshock activation of the $R T L$ parameter, but a quiescence stage is not identified for these events.

We present a brief description of the algorithm of the $R T L$ parameter calculation in the Appendix to make this paper independent from the reference.

\section{Tectonic setting of Northern Italy}

The Apennines are part of a complex collisional plate boundary in the Central Mediterranean, between Africa and Eurasia (Malinverno and Ryan, 1986; Royden et al., 1987). The Northern Apennines arc is formed by several NE verging thrust sheets with eastward progressive migration of the compression front (upper MiocenePleistocene). Three main geodynamic provinces can be distinguished in the Northern Apennines (Bigi et al., 1990):

1) A back-arc basin including the Tyrrhenian Sea and the peri-Tyrrhenian region of the Italian peninsula (extension prevalent since the upper Miocene).

2) A belt-foredeep region along the Adriatic margin characterized by crustal shortening and 


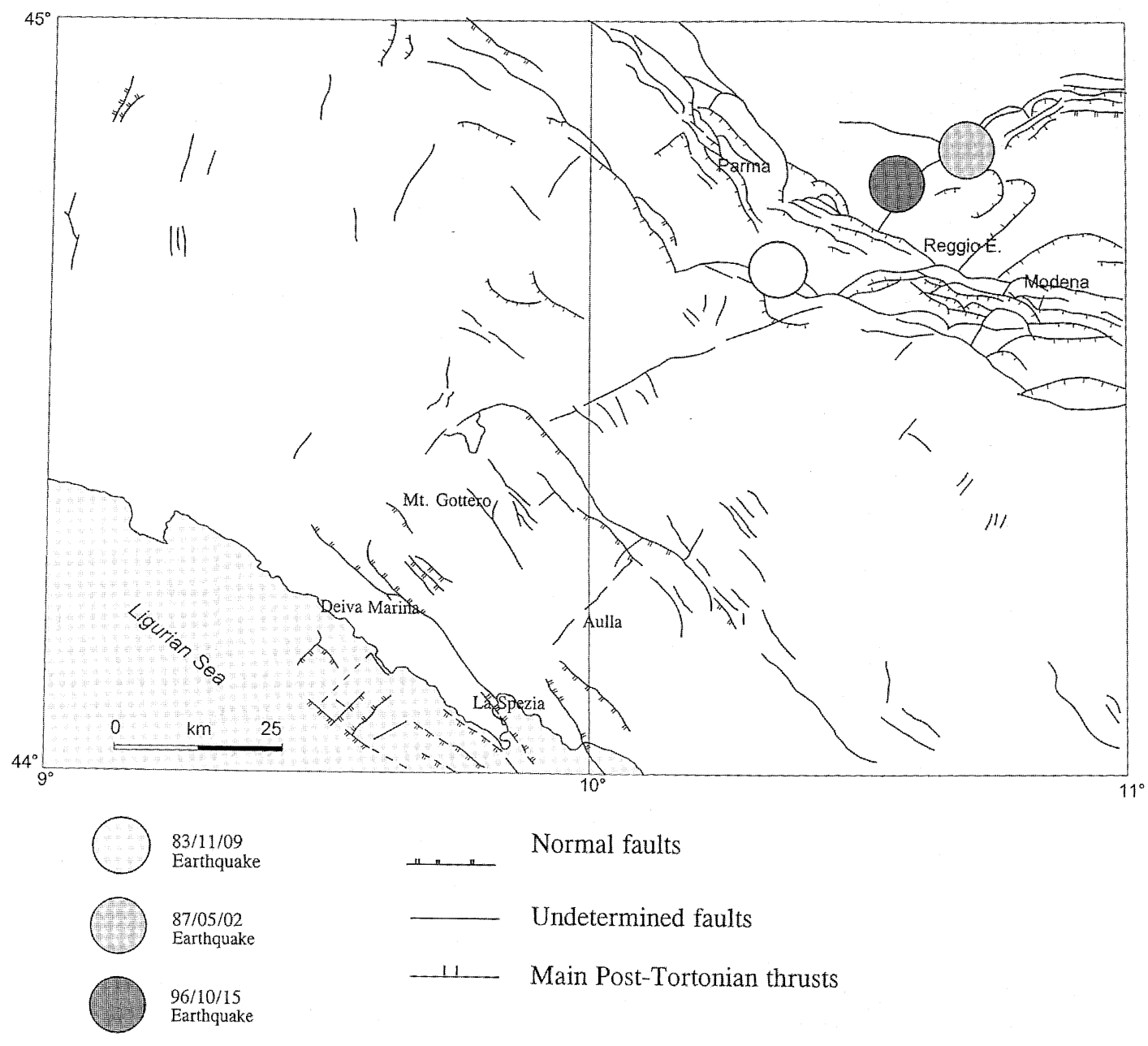

Fig. 1. The map of faults in the area of Reggio Emilia (after Bigi et al., 1990).

westward passive subduction of the Adriatic plate (Reutter, 1981; Royden et al., 1987).

3) A foreland region formed by the great sedimentary basin of the Padana plain and the Adriatic Sea, overlying the continental lithosphere.

Seismic reflection profiles and geological data (Castellarin et al., 1986; Vai, 1987) indicate that the Northern Apennines outer margin is characterized by recent compression, and the inner belt portion is extending. In the Tyrrhenian region, post-orogenic extension was ac- companied by the thinning of the crust, normal faulting, ductile deformation, volcanic activity, and high heat flow (Jolivet et al., 1994). Later, the extension processes affected the Apennines (Plio-Pleistocene), where graben-like structures trending N-S to NW-SE overlying the compression features. In contrast, on the Adriatic margin, the outer front of the belt is probably still under compression (Patacca and Scandone, 1987). The analyses of focal mechanisms of earthquakes, recorded by the seismic network of the Istituto Nazionale di Geofisica (Barba et al., 
1995) during the period of 1988-1995, have confirmed the existence of two adjacent zones of contemporaneous extension and compression in the Northern Apennines (Frepoli and Amato, 1997). The Reggio Emilia area is located in the compression zone.

Figure 1 shows the scheme of faults in the Reggio Emilia area and the location of the epicenters for the three earthquakes evaluated. It is apparent that the structure of the analyzed area is considerably fractured.

\section{Results of the $R T L$ analysis}

The earthquake catalogue of Istituto Nazionale di Geofisica for the period 01/01/1975$29 / 10 / 1996$ was available for $R T L$ analysis of seismicity of the Northern Italy. The algorithm proposed by V. Pisarenko (Sadovsky and Pisarenko, 1991) was used for estimating the completeness of the catalogue. Aftershocks were deleted from the catalogue with the help of the algorithm designed by Molchan and Dmitrieva (1991). Both algorithms were adopted and coded by V. Smirnov. The completeness of the catalogue differ for different time intervals (see table II).

Figures 2, 3 and 4 show the plots of the RTL parameter calculated for the epicenters of the 1983, 1987, and 1996 earthquakes respectively. Earthquakes with magnitudes $3 \leq M \leq 3.8$ are used for calculation of the RTL parameter for the 1983 earthquake. The number of earthquakes with $M \geq 3.0$ is small in the area under consideration (see, for example, fig. 2 top) and we have poor statistics if the restriction $M \geq 3.0$ is used for calculation of the $R T L$ parameter. We have no choice for the case of 1983 earthquake (see table II) but for the cases of 1987 and 1996 earthquakes we can use the data of the catalogue after 1985. Then earthquakes with $2.2 \leq M \leq 3.8$ can be used for calculation of the $R T L$ parameter (see table II). (Maximal magnitude of earthquakes that are used for the calculation of the RTL parameter must be smaller than the magnitude of tested main shocks. We had very limited choice of $M_{\max }$ for main shocks with magnitudes 4.5-4.9 and selected it empirically). The solid vertical line on the plots shows the time of the main earthquakes, whereas the dashed vertical line indicates the commencement of foreshock activation. It is apparent that the interval between the start of the foreshock activation of the RTL parameter and the event is about one year for the earthquakes of 1987 and 1996 and about two months for the earthquake of 1983 .

As indicated in figs. 3 and 4, the process of preparation of the 1987 earthquake is manifested on the plot of the RTL parameter calculated for the epicenter of the 1996 earthquake and vice versa. It was expected, since the distance between epicenters of these two earthquakes is about $10 \mathrm{~km}$ and the value of the $\alpha=\frac{r_{i}}{l_{i}}$ parameter, which characterizes the «proximity» of the event to the tested point, is equal to 1.98 . (Here $l_{i}$ - the linear size of the earthquake focus of 1987 calculated from the empirical relation between the characteristic fault length and the magnitude while $r_{i}$ is the distance between the epicenters of earthquakes of 1987 and of 1996). To make an estimation of the linear size of earthquake focus we used the relation: $\log \left(l_{i}\right)=$ $=0.44 M-1.289$ applicable to Greece seismicity (Papadopoulos and Voidomatis,1987). Possible small errors of the coefficients of this relation do not change the behaviour of parameter $R T L$ essentially (see Appendix).

Table II. The results of analysis of completeness of the catalogue for different time intervals.

\begin{tabular}{ccccc}
\hline \hline Time interval & Number of events & $B$-value & Dispersion of $B$-value & $M_{\min }$ \\
\hline $1975 / 01-1979 / 12$ & 217 & 0.7929 & 0.09 & 3.0 \\
$1980 / 01-1985 / 12$ & 313 & 0.9915 & 0.08 & 2.8 \\
$1985 / 12-1989 / 12$ & 1272 & 1.0351 & 0.04 & 2.2 \\
$1990 / 01-1996 / 10$ & 2210 & 1.1256 & 0.04 & 2.2 \\
\hline
\end{tabular}



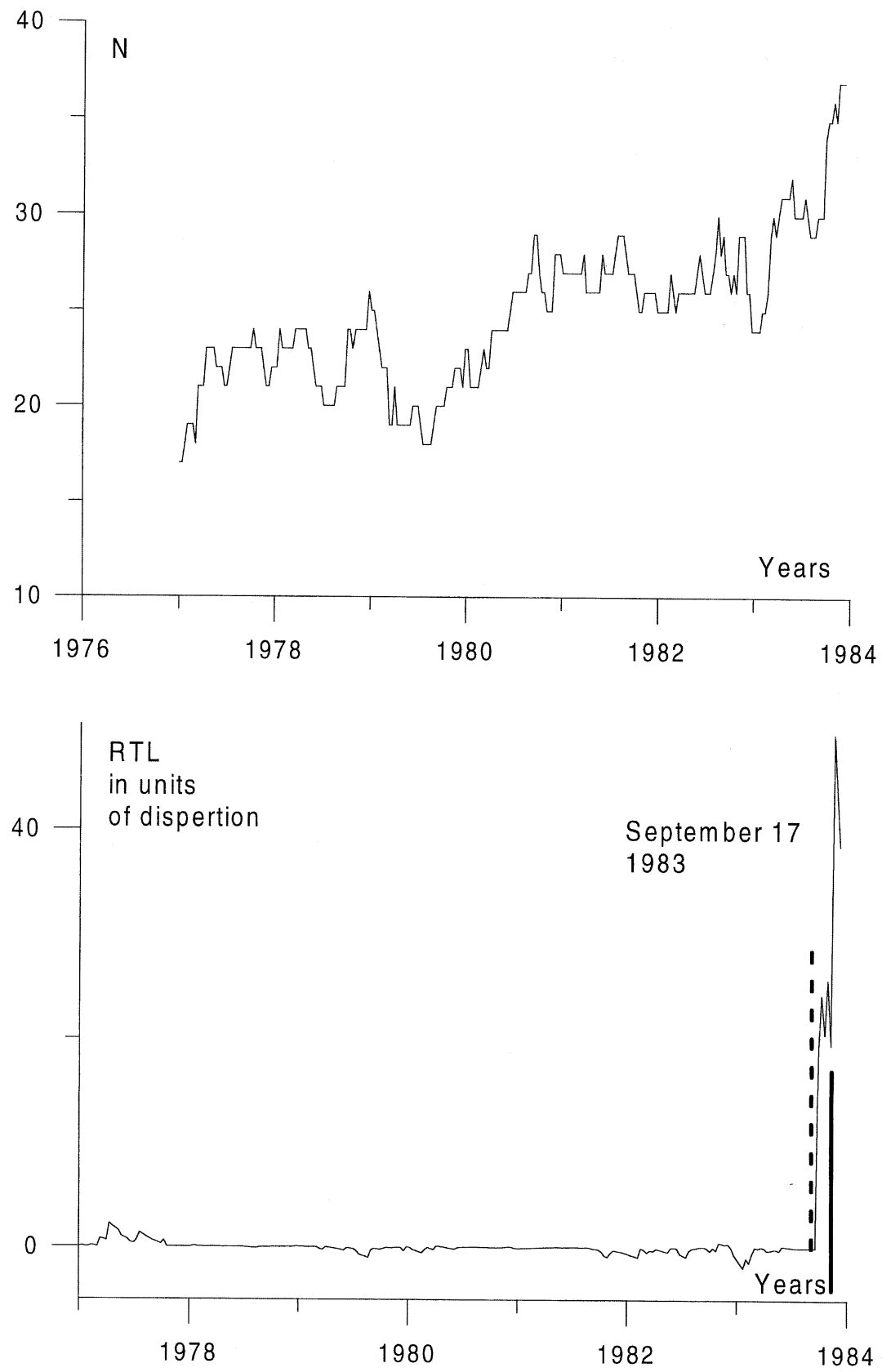

Fig. 2. The RTL plot is calculated for the epicenter of the 1983.11 .09 earthquake (Lat. 44.7N, Long. 10.34E). The solid vertical line in plot shows the time of the earthquake (November 11, 1983), whereas the dashed vertical line indicates the time of commencement of foreshock activation (September 17, 1983). The top plot presents the plot of number of events $N$ with $3.0 \leq M \leq 3.8$ that are used for calculation of the RTL parameter. 

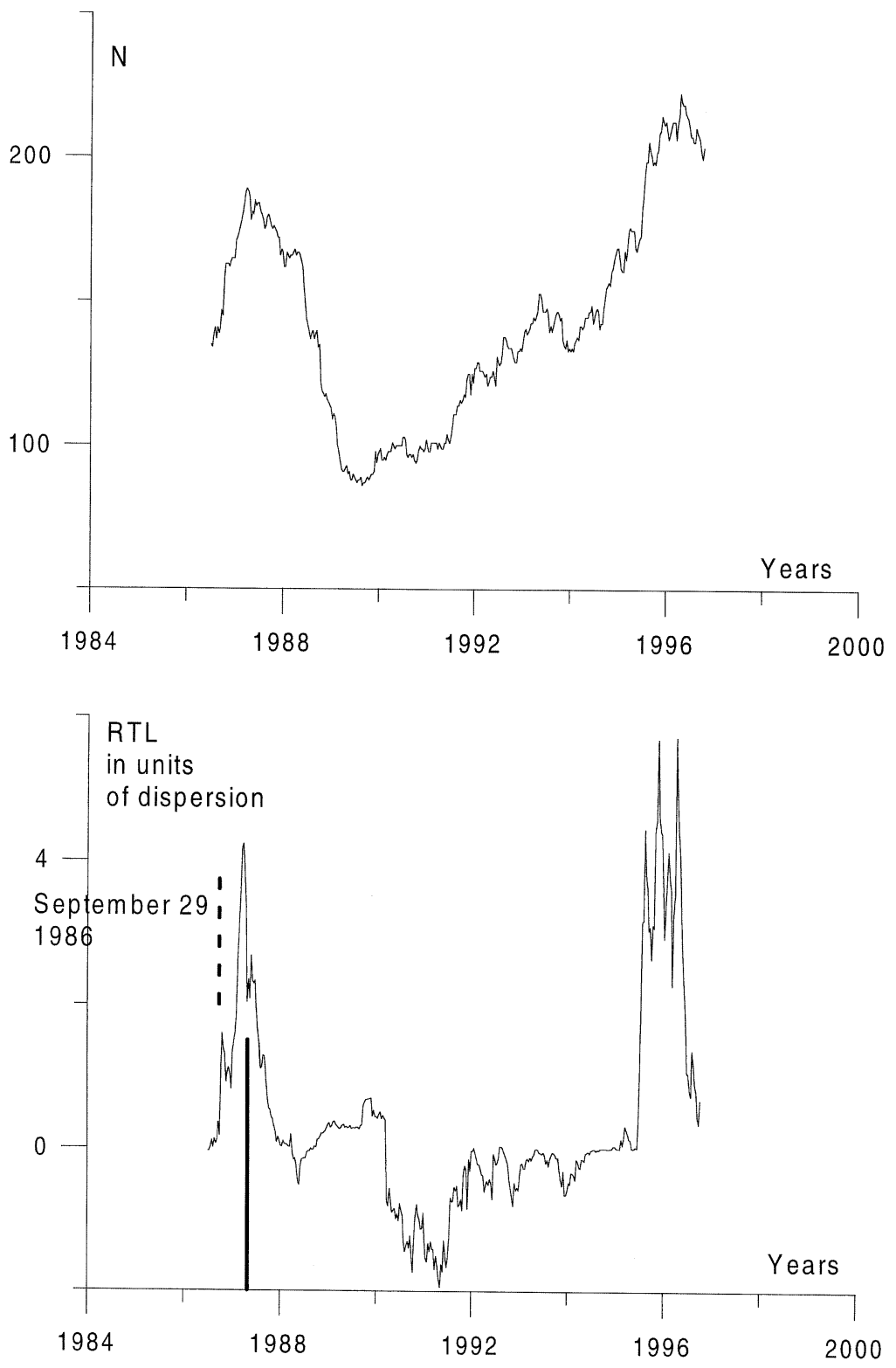

Fig. 3. The $R T L$ plot is calculated for the epicenter of the 1987.05.02 earthquake (Lat. 44.81N, Long. 10.72E). The solid vertical line on the plot shows the time of the earthquake (May 2, 1987), whereas the dashed vertical line indicates the time of commencement of foreshock activation (September 29, 1986). The top plot presents the plot of number of events $N$ with $2.2 \leq M \leq 3.8$ involved in the calculation of the $R T L$ parameter. The process of preparation of the 1996 earthquake is manifested on the plot of the $R T L$ parameter calculated for the epicenter of the 1987 earthquake. It is expected, since the distance between epicenters of these earthquakes is about $10 \mathrm{~km}$ and the value of $a$ parameter, which characterizes the «proximity» of the event to the tested point, is equal to 1.98 . 

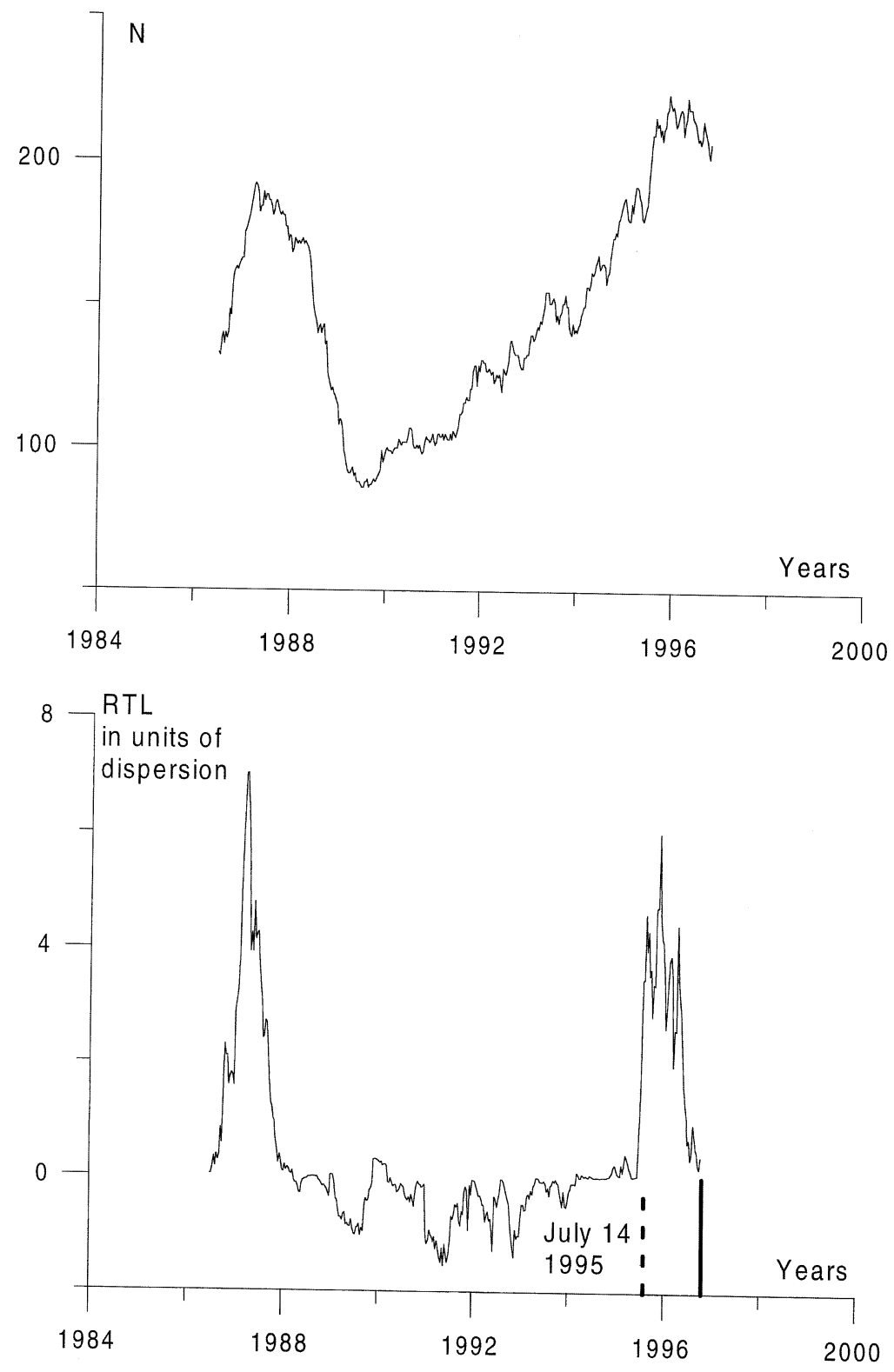

Fig. 4. The RTL plot is calculated for the epicenter of the 1996.10.15 earthquake (Lat. 44.78N, Long. 10.61E). The solid vertical line on the plot shows the time of the earthquake, whereas the dashed vertical line indicates the time of commencement of foreshock activation. The top plot presents the plot of number of events $N$ with $2.2 \leq M \leq 3.8$ involved in the calculation of the $R T L$ parameter. The process of preparation of the 1987 earthquake is manifested on the plot of the RTL parameter calculated for the epicenter of the 1996 earthquake. It is expected, since the distance between epicenters of these earthquakes is about $10 \mathrm{~km}$ and the value of $a$ parameter, which characterizes the «proximity» of the event to the tested point, is equal to 1.98 . 
The plots of number of events $N(t)$ involved in the calculation of the $R T L$ parameter are also presented in figs. 2, 3 and 4 .

To analyze the influence of weak earthquakes we calculated the $R T L$ parameter for different values of $M_{\min }$. The $R T L$ plots that are calculated for the epicenter of the 1996 earthquake (Lat. $44.78 \mathrm{~N}$, Long. 10.61E) for $M_{\min }$ equal to $2.5,2.8$ and 3.0 are presented in fig. 5a-d. One can see that activation of the $R T L$ parameter before 1987 and 1996 earthquakes is observed for all these cases.
We discussed in the Introduction that strong earthquakes usually occurred when the $R T L$ parameter is restored to its perennial background level after a quiescence stage as a result of followed «foreshock» activation. The quiescence stage is not observed for the analyzed events. These earthquakes occurred when a «foreshock» activation of the $R T L$ parameter began to decrease but the $R T L$ parameter did not necessarily achieve its background level. The $R T L$ parameter even increases again during approximately ten days after the 1983 main shock (we
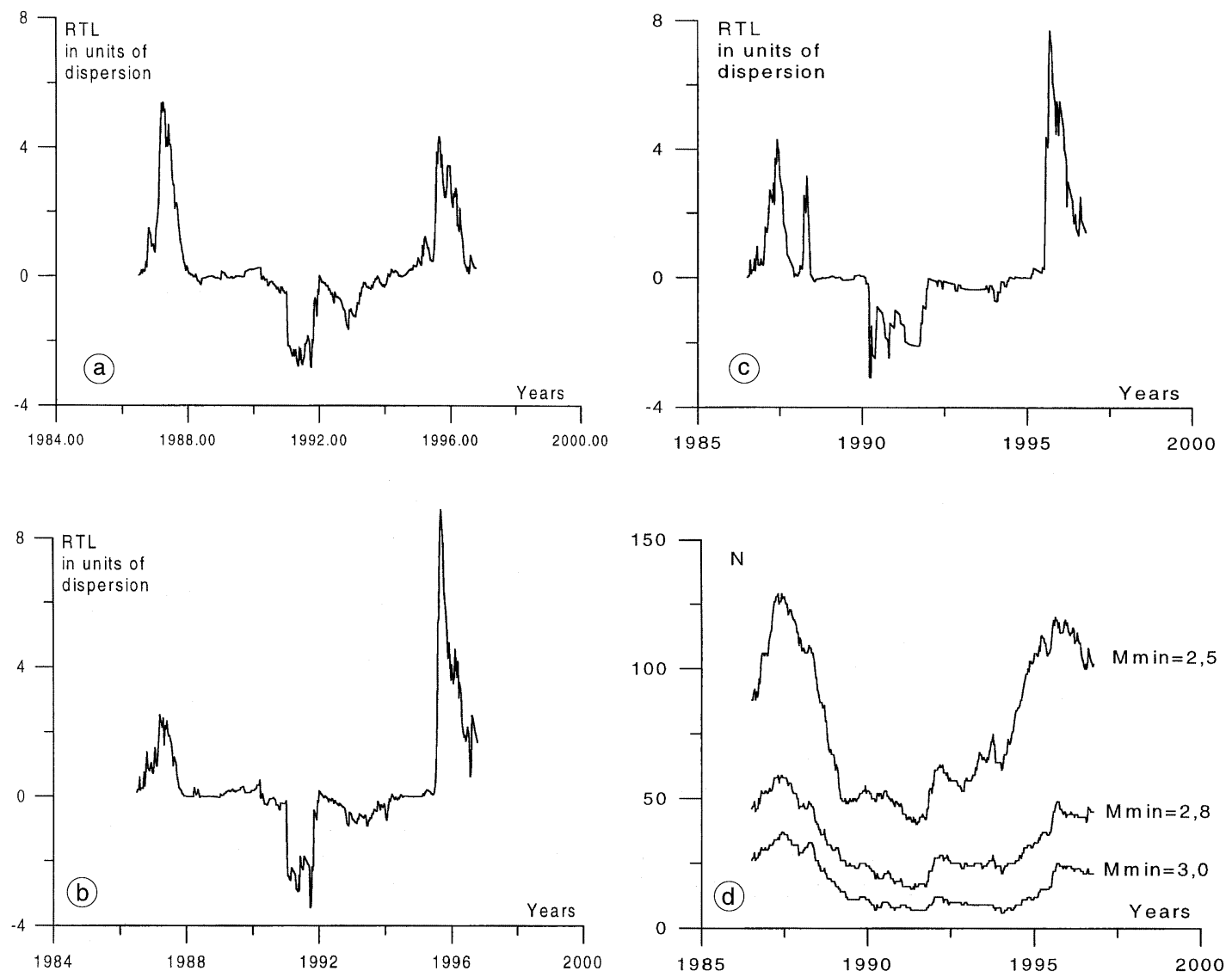

Fig. 5a-d. The RTL plots are calculated for the epicenter of the 1996.10 .15 earthquake (Lat. 44.78N, Long. $10.61 \mathrm{E}$ ) for $M_{\min }$ equal to $2.5(\mathrm{a}), 2.8(\mathrm{~b})$, and 3.0 (c). One can see that activation of the $R T L$ parameter related with the preparation of 1987 and 1996 earthquakes is observed for all these cases. Plots of number of analyzed earthquakes for these three cases are presented in fig. $5 \mathrm{~d}$. 


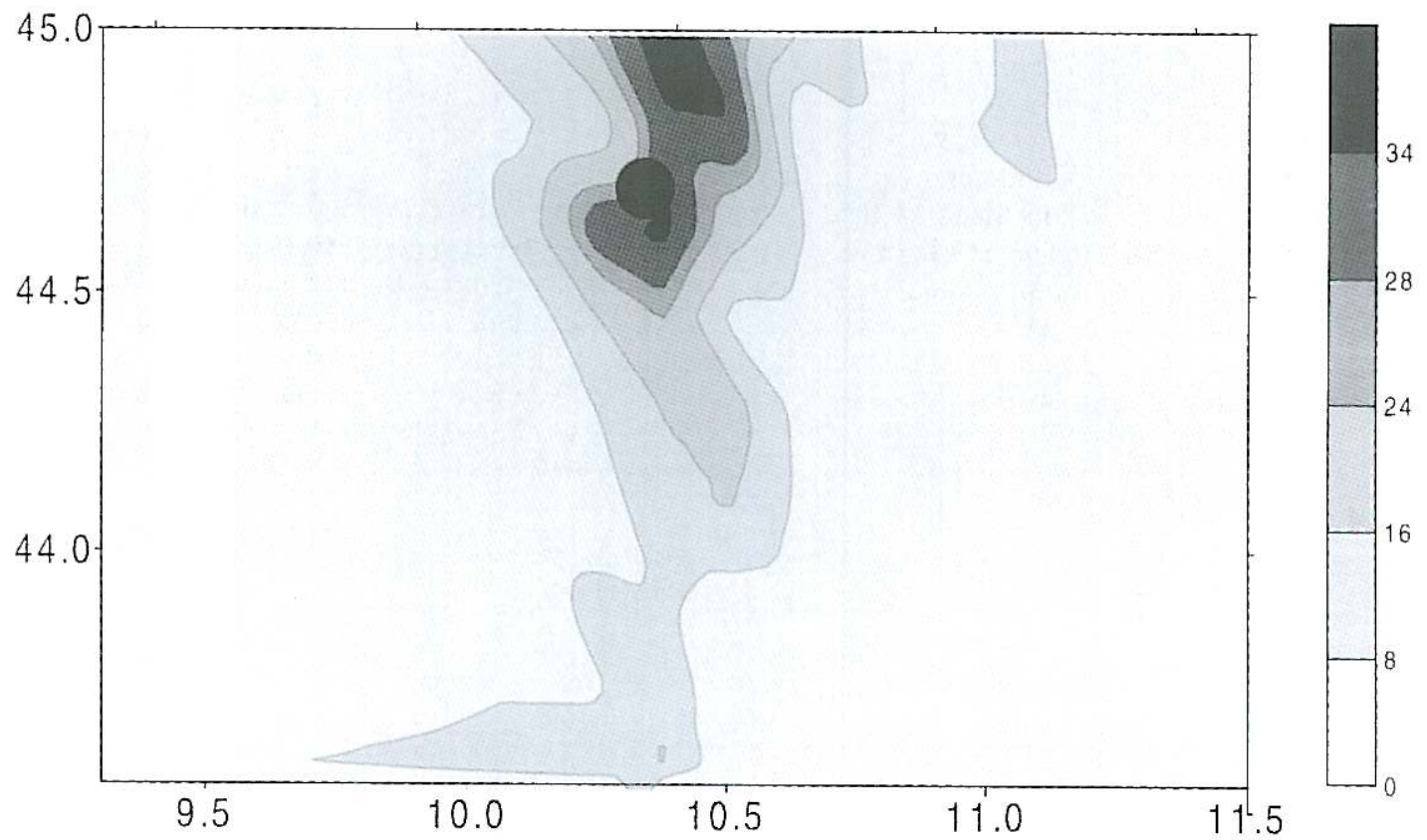

Fig. 6a. The map displays the distribution of maximal values of the RTL parameter in the area of epicenter of the 1983.11.09 earthquake for the time interval $83 / 01-84 / 01$. The step of grid of calculation is $15 \mathrm{~km}$. Black circle indicate main shock.

recall that the time step of calculation of the $R T L$ parameter is equal to ten days).

Figure 6a,b, presents maps of a space distribution of maximal values of the $R T L$ parameter during a one-year time interval before the analyzed earthquakes. A grid with a step equal to $15 \mathrm{~km}$ was used for construction of the maps. One can see that the 1983 main shock is located in the area of maximal values of the $R T L$ parameter but epicenters of two other earthquakes are located in areas of intermediate values of this parameter. An additional analysis of seismicity and geological structure of a region is needed to make a conclusion about the location of the future earthquake.

\section{Discussion}

The retrospective calculations of the $R T L$ parameter for several strong earthquakes on Kamchatka, in Caucasus and in Greece (Sobolev and Tyupkin, 1996a,b, 1998; Sobolev et al., 1997) show that in the interval of two to three years before an earthquake, the seismicity of its epicentral area had a quiescence stage followed by «foreshock» activation. The RTL analysis of seismicity in the area of Reggio Emilia has shown that all moderate-size earthquakes with $M \geq 4.5$, occurring over the time period 1975 1996, are forestalled by foreshock activation of the $R T L$ parameter, but a quiescence stage is not identified for these events. We believe that a quiescence stage is poorly indicated because the analyzed earthquakes have relatively small magnitudes (in comparison with strong earthquakes of Kamchatka and the Caucasus).

The existence of activation of the RTL parameter before the earthquakes with $M \geq 4.5$ is probably a local effect of the Reggio Emilia area. It can be connected with considerably fractured structure of this area. Activation of the $R T L$ parameter is not observed for the earth- 


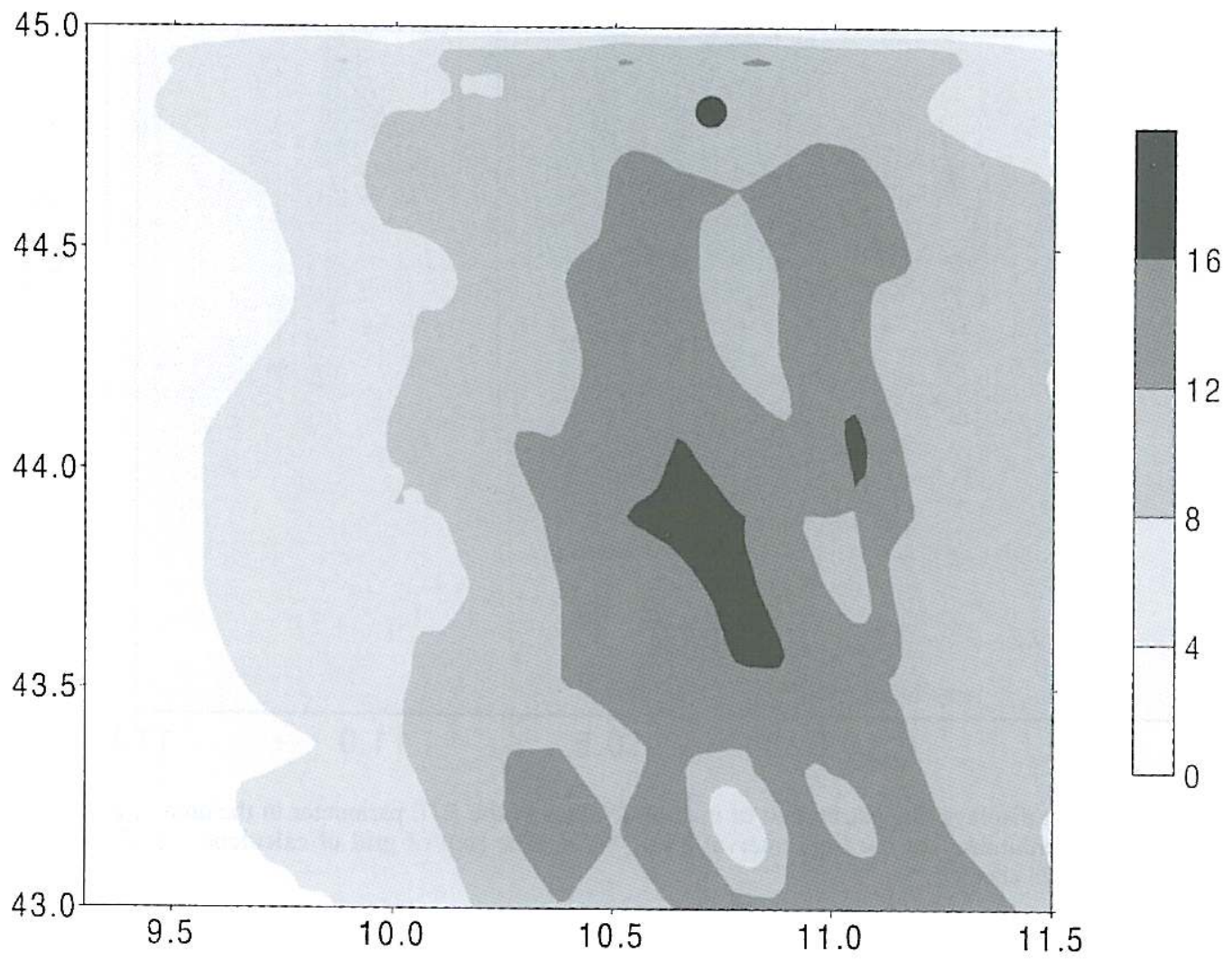

Fig. 6b. The map displays the distribution of maximal values of the RTL parameter in the area of epicenter of the 1987.05.02 earthquake for the time interval 86/08-87/08. The step of grid of calculation is $15 \mathrm{~km}$. Black circle indicate main shock.

quake that took place in October 1995 in the Lunigiana area (Lat. 44.21 N, Long. 10.08E) with $M=4.8$. The areas of Reggio Emilia and Lunigiana belong to different seismotectonic provinces, which probably accounts for the difference in seismic regimes in these areas. In particular, the Reggio Emilia area is located in the compression zone and the Lunigiana area is under the extensional tectonic regime.

The results of analysis of foreshock statistics for Italy that was obtained by Console et al. (1993) confirm our supposition that the RTL foreshock activation discussed above is a local effect of the Reggio Emilia area. Unfortunately we have too few statistics to make a more or less definite conclusion that the foreshock activation of the $R T L$ parameter is typical for this area and can be used as a precursor of earthquakes with $M \geq 4.5$. Only subsequent earthquakes with $M \geq 4.5$ in the Reggio Emilia area will confirm or invalidate this finding.

\section{Conclusions}

The analysis of seismicity in the Reggio Emilia area has shown that all three moderatesize earthquakes with $M \geq 4.5$ that occurred in the area during the period 1975-1996 were forestalled by activation of weak earthquakes. The $R T L$ parameter indicates this foreshock activation. 


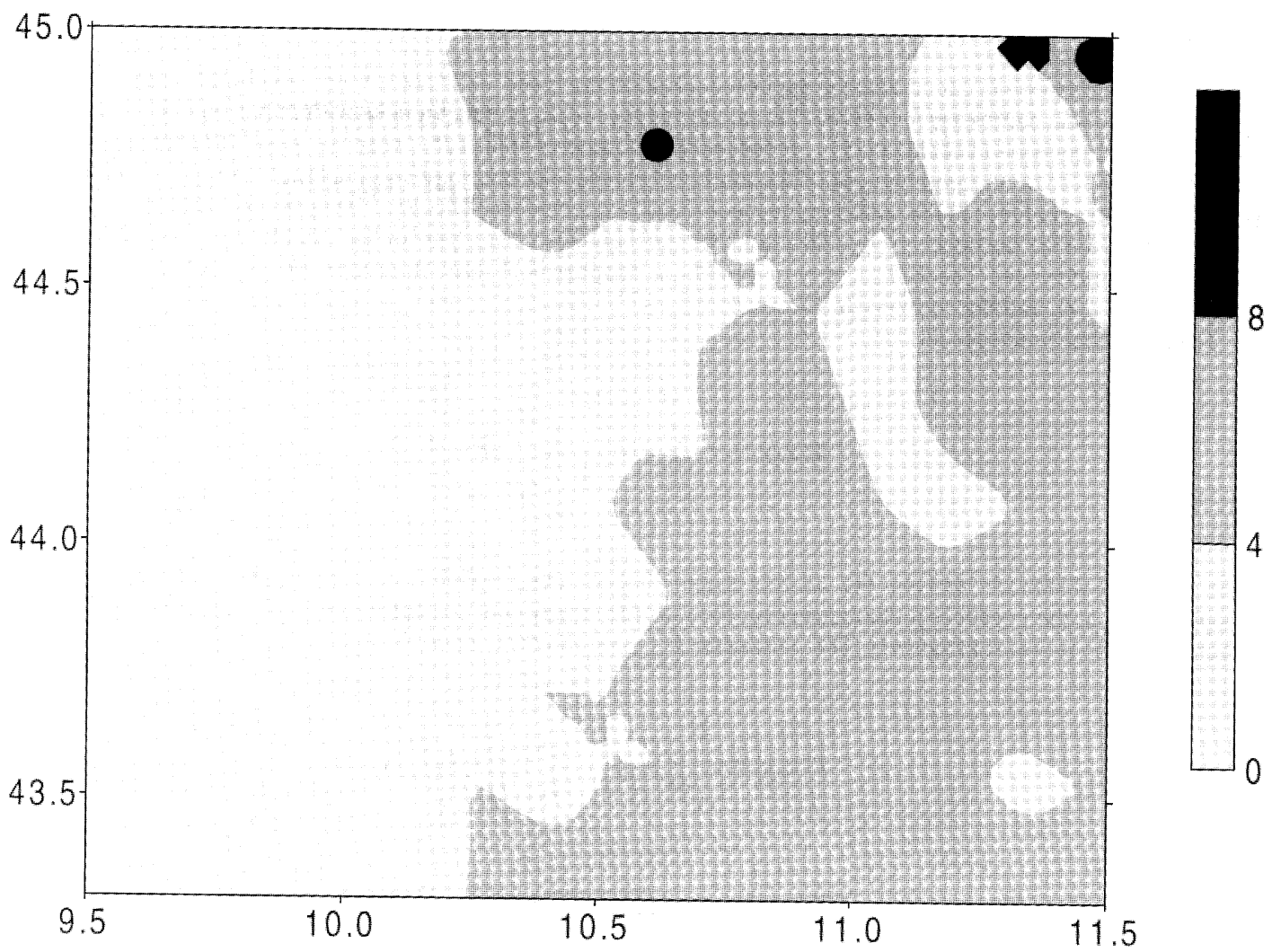

Fig. 6c. The map displays the distribution of maximal values of the $R T L$ parameter in the area of epicenter of the 1996.10 .15 earthquake for the time interval $95 / 11-96 / 11$. The step of grid of calculation is $15 \mathrm{~km}$. Black circle indicate main shock.

The time interval between the commencement of the foreshock activation of the RTL parameter and the main shock was about one year for the 1987 and 1996 earthquakes and about three months for the 1983 earthquake.

The quiescence stage was not observed before the analyzed events. These earthquakes occurred when a «foreshock» activation of the $R T L$ parameter began to decrease but the RTL parameter did not necessarily achieve its perennial background level.

The activation of the RTL parameter before the earthquakes with $M \geq 4.5$ probably is a local effect of the Reggio Emilia area. For example, an activation of the RTL parameter is not observed for the October 1995 earthquake $(M=4.8)$ located at $44.21^{\circ} \mathrm{N}, 10.08^{\circ} \mathrm{E}$, which occurred in a different seismotectonic province of Northern Italy (in the Lunigiana area). The activation of the $R T L$ parameter that is related with the process of clustering of weak earthquakes but did not precede the earthquakes with $M \geq 4.5$ is also observed for other areas of Italy

\section{Acknowledgements}

We are grateful to Prof. G.A. Sobolev for very useful discussions and to Dr. R. Console, Dr. V. Peçi, Dr. I.V. Kuznetsov and Prof. G.F. Panza for important comments. The work was supported in part by Russian Basic Research Foundation, grant No. 96-05-65439 


\section{Appendix}

The RTL parameter is calculated for the tested point on the Earth's surface $x=(x, y)$ as function of time $t$. The value of prognostic parameter $R T L(x, y, t)$ is calculated from data on earthquakes with magnitude $M_{\min }<M<M_{\max }$ which fall into the time interval $\left(t-T_{\max }, t\right)$ and within a circle of radius $R_{\max }$ with the center located at the tested point $(x, y)$. The level of completeness of the analyzed earthquake catalogue defines the value of $M_{\text {min }}$. The value of $M_{\max }$ must be smaller than the tested main shocks and is selected empirically. The optimal values of the $R_{\max }$ and $T_{\max }$ that characterize the space-time restrictions for earthquakes taking part in the calculation of the $R T L(x, y, t)$ are selected empirically. The $R T L(x, y, t)$ parameter is composed of three functions: the epicentral $R(x, y, t)$, the temporal $T(x, y, t)$, and the source size $L(x, y, t)$.

The indicated functions are

$$
R(x, y, t)=\left[\sum_{i=1}^{n} \exp \left(-\frac{r_{i}}{r_{0}}\right)\right]-R s .
$$

Here $r_{i}$ are the distances between the seismic events that occurred before time $t$ and the tested point $x$ (point of prognosis); $r_{0}$ is the coefficient characterizing the rate of reduction of the influence of the more remote seismic events from the point of prognosis. The parameter $R_{\max }$ (see above) is equal to $2 r_{0}$

$$
T(x, y, t)=\left[\sum_{i=1}^{n} \exp \left(-\frac{t-t_{i}}{t_{0}}\right)\right]-T s .
$$

Here $t_{i}$ is the time of the preceding events. The $t_{0}$ parameter characterizes the rate of reduction of the influence of preceding seismic events as they recede into the past from the moment of prediction. The parameter $T_{\max }$ (see above) is equal to $2 t_{0}$

$$
L(x, y, t)=\sum_{i=1}^{n} \frac{l_{i}}{r_{i}}-L s .
$$

Here $l_{i}$ is the size of source of the earthquake proceeding the moment of prediction. The value of $l_{i}$ is calculated in accordance with the empirical relation $\log \left(l_{i}\right)=a \cdot M-b$ between the size of source $l_{i}$ and the magnitude of earthquake $M_{i} . R s, T s$ and $L s$ are corrections for the trend.

The functions $R, T$ and $L$ are reduced to a single dispersion. The prognostic parameter $R T L$ is calculated as a product of the three functions described by expressions (A.1)-(A.3) and the value of the RTL parameter is measured in the units of its dispersion.

$a$ and $b$ coefficients in the formula (A.3) differ for different regions (see, for example, Wells and Coppersmith, 1994). We used $a=0.44$ and $b=1.289$ in the present study. These values of $a$ and $b$ coefficients are applicable to Greece seismicity (Papadopoulos and Voidomatis, 1987). It is possible that these coefficients are slightly different for Italy but small errors $\delta a$ and $\delta b$ of estimation of $a$ and $b$ coefficients lead to small variation of the function $L$. Namely, function $L$ does not depend on the coefficient $b$. Direct calculations give that variation $|\delta a| \leq 0.2$ does not change the behaviour of parameter $R T L$ essentially.

The activation of seismicity and seismic quiescence in the vicinity of the tested point causes the growth or decline of the $R T L$ parameter, respectively, against the background value.

In the present study, we used the same parameters of the $R T L$ algorithm as were used in the papers of Sobolev and Tyupkin (1996a,b, 1998; Sobolev et al., 1997; $\left(r_{0}=50 \mathrm{~km}, t_{0}=1\right.$ year, time step $=10$ days) 


\section{REFERENCES}

Barba, S., R. Di Giovambattista and G. Smriglio (1995): Italian seismic databank allows on-line access, Eos, Trans. Am. Geophys. Un., 76, 89

Bigi, G., D. Cosentino, M. Parotto, R. SARtori and P. SCANDONE (1990): Structural model of Italy, 1:500 000, PFG-CNR, Quad. Ric. Sci, p. 114.

Castellarin, A., C. Eva, G. Giglia and G.B. Vai (1986): Analisi strutturale del Fronte Appenninico Padano, G. Geol., 47 (1-2), 47.

Console, R., M. Murru and B. Alessandrini (1993): Foreshock statistics and their possible relationship to earthquake prediction in the Italian region, Bull. Seismol. Soc. Am., 83, 1248-1263.

Costa, G., I. Orozova-StanishKova, G.F. Panza and I.M. Rotwain (1996): Seismotectonic models and CN algorithm: the case of Italy, Pageoph, 147, 119-130.

Frepoli, A. and A. AmAto (1997): Contemporaneous extension and compression in the Northern Apennines from earthquake fault-plane solutions, Geophys. J. Int., 129, 368-388.

Jolivet, L., J.M DANiel, C.Truffert and B. GofFÈ (1994): Exhumation of deep crustal metamorphic rocks and crustal extension in arc and back-arc regions, Lithos, 33

KapYlova, G.N., YU.K. Zhalyajeva and E.P. LATYPOV (1998): Variations of weak seismicity in the epicentral zones of large $(M>6.8)$ Kamchatka earthquakes (by the results of calculating the RTL function, G.A. SOBOLEV, Yu.S. TYUPKIN et al., 1996), in Kronotskoye Earthquake of December 5, 1997 on Kamchatka. Precursors, Properties, Effects, edited by E.I. GoRDEEV, B.V. IVANOV and A.V. VIKULIN, Kamchatka, 158-169.

MALINVERNO, A. and W.B.F. RYAN (1986): Extension in the Tyrrhenian Sea and shortening in the Apennines as result of arc migration driven by sinking of the lithosphere, Tectonics, 5, 227-245.

Molchan, G. and T. DMITRIEVA (1991): Identification of aftershocks: review and new approaches, Comp. Seismol., 24, p. 19 (in Russian).

Papadopoulos, G.A. and P. Voidomatis (1987): Evidence for periodic seismicity in the inner Aegean seismic zone, Pageoph, 125 (4), 613-628.

PATACCA, E. and P. SCANDONE (1987): Segmentation and configuration of subducted lithosphere in Italy: an important control on thrust-belt and foredeep-basin evolution, Geology, 25, 714-717.

Purcaru, G. and K. PAWELzIK (1991a): A new tool for identification of anomalous seismicity patterns, in International Conference on Earthquake Prediction:
State-of-the-Art, Strasbourg, 108-115.

Purcaru, G. and K. PAWELZIK (1991b): Simultaneous Variation of Observables (SVO) method: a new tool for identification of anomalous seismicity patterns, Eos, Trans. Am. Geophys. Un., 72 (44), 322.

REUTTER, K.J. (1981): A trench-forearc model for the Northern Apennines, in Sedimentary Basins of Mediterranean Margins, edited by F.C. WEZEL, CNR Italian Project of Oceanography (Tecnoprint, Bologna), pp. 433.

Royden, L., E. Patacca, and P. ScAndone (1987): Segmentation and configuration of subducted lithosphere in Italy: an important control on thrust-belt and foredeep-basin evolution, Geology, 15, 714-717.

SAdOVSKY, M.A. and V.F. PISARENKO (1991): Seismic Processes in Block Structure Medium (Moscow, Nauka), pp. 96 (in Russia).

SobOLEV, G.A. (1992): Earthquake prediction in the USSR: fundamental principles, J. Earthquake Predic. Res., 1 (1), 21-42.

Sobolev, G.A. (1993): Basic Principles of Earthquake Prediction (M. Nauka), pp. 313.

SoboleV, G.A. and YU.S. TYUPKIN (1996a): Lowseismicity precursors of large earthquakes in Kamchatka, Vulkanologiya i Seismologiya, 4, 64-74 (in Russian). Translation in English: Volcanol. Seismol., 18, 433-446 (1997).

SoboleV, G.A. and YU.S. TYUPKIN (1996b): New method of intermediate-term earthquake prediction, in Seismology in Europe, ESC, Reykjavik, pp. 229.

SoboleV, G.A. and YU.S. TYUPKIN (1998): Stages of preparation, seismological precursors and earthquake prediction in Kamchatka, Vulkanologiya I Seismologiya (in Russian), 6, 17-24.

Sobolev, G.A., Yu. S. TYUPKIN and A. ZaVyalov (1997): Map of expected earthquakes algorithm and RTL prognostic parameter: joint application, in The 29th General Assembly of the IASPEI, abstracts, p. 77.

VAI, G.B. (1987): Migrazione complessa del sistema fronte deformativo-avanfossa-cercine periferico: il caso dell'Appennino Settentrionale (1987), Mem. Soc. Geol. It., 38, 95-105, 5 ff., 1 tav.

WeLlS, D.L. and K.J. COOPERSMITH (1994): New empirical relations among magnitude, rupture length, rupture width, rupture area, and surface displacement, BSSA, 84, 974-1002.

WYSS, M. and R.E. HABERMANN (1988): Precursory quiescence, Pageoph, 126 (2/4), 319-332.

ZSCHAU, J. (1995): SEISMOLAP: a quantification of seismic quiescence and clustering, in $I U G G, X I$ General Assembly, Boulder, Co., USA, July 2-14 1995, abstracts, p. 389. 